OPEN ACCESS

Edited by:

Miriam Postan,

Consejo Nacional de Investigaciones

Cientificas y Técnicas (CONICET),

Argentina

Reviewed by:

Sharvan Sehrawat,

Indian Institute of Science Education

and Research, Mohali, India

Rodnei Dennis Rossoni,

São Paulo State University, Brazil

*Correspondence:

Thais F. C. Fraga-Silva

thaisfragasilva@gmail.com

Specialty section:

This article was submitted to

Microbial Immunology,

a section of the journal

Frontiers in Microbiology

Received: 27 June 2018 Accepted: 18 November 2018

Published: 08 January 2019

Citation:

Sanches MD, Mimura LAN,

Oliveira $L R C$, Ishikawa $L L W$, Garces HG, Bagagli E, Sartori A, Kurokawa CS and Fraga-Silva TFC

(2019) Differential Behavior

of Non-albicans Candida Species

in the Central Nervous System

of Immunocompetent

and Immunosuppressed Mice.

Front. Microbiol. 9:2968.

doi: 10.3389/fmicb.2018.02968

\section{Differential Behavior of Non-albicans Candida Species in the Central Nervous System of Immunocompetent and Immunosuppressed Mice}

\author{
Marcelo D'Alessandre Sanches', Luiza A. N. Mimura², Larissa R. C. Oliveira², \\ Larissa L. W. Ishikawa', Hans G. Garces ${ }^{2}$, Eduardo Bagagli'2, Alexandrina Sartori², \\ Cilmery Suemi Kurokawa ${ }^{1}$ and Thais F. C. Fraga-Silva ${ }^{1 *}$
}

\section{'Botucatu Medical School, São Paulo State University (UNESP), Botucatu, Brazil, ${ }^{2}$ Institute of Biosciences, São Paulo State University (UNESP), Botucatu, Brazil}

The genus Candida includes commensal fungi that can cause local and systemic infections, frequently involving vital organs as the central nervous system (CNS). Candida spp. occupy the fourth place among infections that affect the CNS. Although the incidence of Candida albicans is decreasing among patients under immunosuppressive therapies, the incidence of non-albicans Candida is increasing. In this context, the objective of this work was to evaluate the ability of non-albicans Candida species to spread to the CNS of immunocompetent and immunosuppressed mice. Adult female C57BL/6 mice were treated with prednisolone, intravenously infected with Candida glabrata, Candida krusei and Candida parapsilosis yeasts and then evaluated at the 3rd and 14th days after infection. All Candida species disseminated to the brain from immunocompetent animals and induced local inflammation at the third day postinfection. The immunosuppression resulted in body weight loss, leukopenia and reduced IL-2 production by spleen cell cultures. Higher fungal loads were recovered from the CNS of immunosuppressed mice. Inflammatory infiltration associated to a Th1 subset profile was higher in brain samples from C. krusei immunosuppressed mice compared with immunocompetent ones. Additionally, C. krusei was able to transform into pseudohypha inside microglia in vitro infected cells and also to induce elevated nitric oxide production. Altogether, these results indicate that C. glabrata, C. krusei and C. parapsilosis are able to disseminate to the CNS and promote local inflammation in both immunocompetent and immunosuppressed mice. C. krusei displayed a distinct behavior at the CNS triggering a local Th1 profile. The possible contribution of these nonalbicans Candida species to other CNS pathologies as multiple sclerosis, Parkinson's and Alzheimer's diseases deserves further attention.

Keywords: Candida spp., fungal infections, prednisolone, neuroinflammation, microglia 


\section{INTRODUCTION}

The genus Candida includes commensal fungi that live in the human oral cavity, gastrointestinal and genitourinary tracts. In certain conditions, such as changes in the microbiota and loss of integrity of epithelial barriers, their excessive growth or translocation through the intestine may occur and cause local and systemic infections (Eggimann et al., 2003). Thus, Candida spp. are considered opportunistic commensal pathogens that promote infection under host predisposing conditions.

Systemic Candida infections affect vital organs, including the central nervous system (CNS) (Li et al., 2017). Morbidities in these infections are severe and comprise a broad spectrum of clinical symptoms, including brain abscesses, meningitis/meningoencephalitis, stroke/vasculitis, and death (Murthy and Sundaram, 2014). The spread of this pathogen to the brain is more common in newborns (Faix and Chapman, 2003) and this is also responsible for most of the brain abscesses in immunocompromised patients (Yampolsky et al., 2010). Candida spp. occupy the fourth place among infections in the CNS (Panackal and Williamson, 2015). Non-albicans Candida species are also found in the CNS and the most frequent pathogenic species are Candida glabrata, Candida parapsilosis, Candida tropicalis and Candida krusei (Storti et al., 2012; Pfaller et al., 2014; Turner and Butler, 2014). The most common risk factors for these infections are associated with the use of catheters (venous, urinary and arterial), administration of broad-spectrum antibiotics, mechanical ventilation, nasogastric intubation, enteral and parenteral nutrition, and treatment with systemic corticosteroids (Jordán et al., 2014).

To invade the CNS, fungi must cross the blood-brain barrier (BBB). Candida albicans is able to pass through the human brain microvascular endothelial cells (HBMECs) via transcytosis and it is also able to generate pseudohyphae inside these cells (Jong et al., 2001). This process requires the initial binding of fungal invasins, ALS3 and SSA1, to proteins expressed in HBMECs. ALS3 binds to the gp96 heat shock protein whereas SSA1 binds to other receptor in HBMECs (Liu et al., 2011). These proteins were initially described and studied only in C. albicans. ALS3 was later also identified in non-albicans Candida species, including C. dubliniensis and C. tropicalis (Hoyer et al., 2001) and an ALS3 homolog (CpALS7) was described in C. parapsilosis (Bertini et al., 2016).

Neurodegenerative pathologies such as Alzheimer's disease, Parkinson's disease, amyotrophic lateral sclerosis and multiple sclerosis (MS), constitute a heterogeneous group of CNS disorders that are characterized by a slow and irreversible loss of neuronal functions. Although their etiology remains largely unknown (Pisa et al., 2015), some studies suggested that CNS infections could act as cofactors in the development of these diseases (Mattson, 2012; Saroukolaei et al., 2016; Góralska et al., 2018). Evidences observed in MS patients support the possible contribution of Candida infections to the development of neurodegenerative and/or autoimmune diseases. Compared to healthy subjects, MS patients present significantly higher levels of specific antibodies and Candida spp.-derived macromolecules in blood (Benito-León et al., 2010;
Pisa et al., 2011) and in the cerebrospinal fluid (Pisa et al., 2013).

On the other hand Candida spp. infections in MS patients could be a consequence of disease treatment since therapy is mostly relied on immunosuppression to reduce the frequency and severity of exacerbations. Thus, MS acute episodes are usually treated with corticosteroids whereas chronic periods are controlled by immunomodulatory drugs (Gold and Wolinsky, 2010). In this context, prednisolone is a glucocorticoid employed to treat a plethora of chronic inflammatory diseases (De Kruif et al., 2007; Yan et al., 2015) whose anti-inflammatory role is due to its ability to suppress or inhibit the presence of NF-kB transcription factors (Andersson et al., 2005). This possible relationship between immunosuppression triggered by prednisolone therapy with increased fungal load and also with systemic dissemination was recently described in a murine model of gastrointestinal candidiasis (Kobayashi-Sakamoto et al., 2018). In this scenario we could think that fungal infections, including the ones triggered by non-albicans Candida species, could be involved in disease development by previous infections or disease exacerbation by infections associated with immunosuppressive therapy.

Interestingly, the incidence of C. albicans decreased in many countries, especially among patients under immunosuppressive therapies, while the incidence of non-albicans Candida clearly increased (Yapar, 2014; Wu et al., 2017). Similarly to C. albicans, non-albicans Candida species can also reach the CNS, opening up the interesting possibility that they can present distinct neurotropism and also a specific behavior considering their spread to the CNS when hosts are under immunosuppressive therapy. Therefore, in the present study we evaluated the ability of three non-albicans Candida species to spread to the CNS in immunocompetent and immunosuppressed C57BL/6 mice. As expected, immunosuppression enhanced fungal burden in the CNS but C. glabrata, C. krusei and C. parapsilosis species behaved differently.

\section{MATERIALS AND METHODS}

\section{Animals}

Female C57BL/6 mice with 9 to 11 weeks old were purchased from a specific pathogen-free facility at University of São Paulo (USP) (Ribeirão Preto, SP, Brazil). Mice were allocated in cages (maximum five animals per cage) with sterilized food and water ad libitum and were manipulated in accordance with the local Ethics Committee on Use of Animals (CEUA), from São Paulo State University (UNESP) (Botucatu, SP, Brazil).

\section{Experimental Design}

For initial evaluations, 40 immunocompetent mice were allocated into eight groups, with 5 mice per group: 3 days non-infected and 3 days infected mice with C. glabrata, C. krusei and C. parapsilosis and 14 days non-infected and 14 days infected mice with C. glabrata, C. krusei and C. parapsilosis. In the subsequent analyses were used 32 immunocompetent (control - CTL) and 32 immunosuppressed (prednisolone - PRED) animals. Mice were 
allocated into $4 \mathrm{CTL}$ and 4 PRED groups (8 mice per group): non-infected mice, mice infected with C. glabrata, mice infected with C. krusei and mice infected with C. parapsilosis. Clinical parameters were followed for 14-16 days. Immunological and histopathological evaluations were performed at 14 days after infection and 11 days after prednisolone treatment.

\section{Candida spp. Inoculum}

Candida glabrata (H-3479), C. krusei (ATCC 6258), and C. parapsilosis (ATCC 90018) were obtained from the fungal collection of Mycology Laboratory (UNESP, Botucatu, SP, Brazil) where they were stored at $-80^{\circ} \mathrm{C}$ in glycerol stocks. For mice infection, Candida spp. were cultured in Sabouraud-dextrose agar (Difco Laboratories, Detroit, MI, United States) for $24 \mathrm{~h}$, at $37^{\circ} \mathrm{C}$, and carefully washed with sterile saline solution (SSS). The suspensions were centrifuged and washed twice at $450 \times g$ for $5 \mathrm{~min}$ at $4^{\circ} \mathrm{C}$. The fungal concentration was adjusted to $5.0 \times 10^{7}$ viable yeast cells $/ \mathrm{mL}$ in SSS and then inoculated into the lateral tail vein $(0.1 \mathrm{~mL} / \mathrm{animal})$. Fungal suspensions were previously heat-killed to be used for culture stimulation.

\section{Immunosuppression}

The animals were immunosuppressed by administration of two subcutaneous injections of prednisolone (Sigma-Aldrich, St. Louis, MO, United States) at a dose of $100 \mathrm{mg} / \mathrm{kg}$ body weight delivered 1 day before and 3 days after the infection with Candida spp., according to Takakura et al. (2003).

\section{Determination of Fungal Burden}

Fourteen days after infection, mice were anesthetized with ketamine/xylazine and perfused with $10 \mathrm{~mL}$ of SSS. Brain, spinal cord and spleen were collected, weighed and macerated in $1.0 \mathrm{~mL}$ of SSS. Afterward, $0.1 \mathrm{~mL}$ from each tissue homogenate was spread over culture plates containing Sabouraud-dextrose agar (Difco) using a Drigalski $\mathrm{T}$ loop. The plates were then sealed and incubated at $37^{\circ} \mathrm{C}$ for 3 days. The number of colony forming units (CFU) was normalized per gram of tissue and log transformed.

\section{Spleen Cell Culture}

Spleens were initially dissociated with sterile pestles and then the red blood cells were lysed with buffer containing $\mathrm{NH}_{4} \mathrm{Cl}$. The remaining cells were washed with RPMI 1640 (Sigma-Aldrich) medium and the cells were adjusted to $5 \times 10^{6}$ cells $/ \mathrm{mL}$ in RPMI medium supplemented with $10 \%$ heat-inactivated fetal calf serum (Gibco BRL, Grand Island, NY, United States), $2 \mathrm{mM}$ of L-glutamine (Sigma-Aldrich) and $0.1 \%$ antibioticantimycotic (Sigma-Aldrich). Spleen cell cultures were stimulated with heat-killed Candida spp. (5 yeasts/cell) and incubated at $37^{\circ} \mathrm{C}, 5 \% \mathrm{CO}_{2}$ in a humidified incubator for $48 \mathrm{~h}$. Cell-free supernatants were harvested and stored at $-20^{\circ} \mathrm{C}$ for cytokine analysis.

\section{Cytokine Quantification}

Cytokine levels were evaluated by enzyme-linked immunosorbent assay (ELISA) in culture supernatants using
IFN- $\gamma$, IL-5 and IL-10 BD OptEIA Sets (Becton, Dickinson and Company, BD, Franklin, San Diego, CA, United States) and IL-2, IL-6, IL-17, and TNF- $\alpha$ Duosets (R and D Systems, Minneapolis, MN, United States). The assays were performed according to the manufacturer's instructions.

\section{Histopathology of the CNS}

After euthanasia, brain and lumbar spinal cord samples were removed and fixed in 10\% neutral buffered formalin. Paraffin slides with $4 \mu \mathrm{m}$ were stained with hematoxylin and eosin (HE) to evaluate the inflammatory process. A semiquantitative analysis of CNS inflammation was performed according to the following criteria: (0) inflammatory infiltration absent; (1) mild inflammatory infiltration; (2) moderate inflammatory infiltration, and (3) intense inflammatory infiltration.

\section{RT-qPCR}

Frozen brain samples were used for RNA extraction with Trizol reagent (Life Technologies, Carlsbad, CA, United States) and cDNA synthesis (RT-PCR) was performed according to the manufacturer's recommendations (High Capacity RNA-tocDNA converter kit, Life Technologies). Expression of Gata3, Rorc, Foxp3, Tbx21, IFN-y, TNF- $\alpha$, CLEC7A (dectin-1), TLR2, TLR-4 genes was analyzed based on GAPDH reference gene levels. Real Time PCR was performed using Taqman system according to manufacturer's recommendations (Applied Biosystems, Foster City, CA, United States). Gene expression was represented as relative fold difference $\left(2^{-\Delta \Delta \mathrm{Ct}}\right)$ using the Control (non-treated and non-infected) group as the calibrator.

\section{Biofilm Quantification by the XTT Assay}

Candida albicans (SC5314) and the three non-albicans Candida species were grown in YEPD broth (Difco, Sparks, MD, United States) during $24 \mathrm{~h}$. The inoculum was standardized at a concentration of $10^{7}$ cells/mL in RPMI 1640 (Sigma-Aldrich) medium. The specimens $(0.1 \mathrm{~mL}$ of inoculum) were plated in triplicate in 96-well cell culture and incubated at $37^{\circ} \mathrm{C}, 5 \%$ $\mathrm{CO}_{2}$ in a humidified incubator for $24 \mathrm{~h}$. After incubation time intervals of 6,18 , and $24 \mathrm{~h}$, the specimens were carefully washed three times with $0.1 \mathrm{~mL}$ of phosphate-buffered saline (PBS) and the biofilm formed was evaluated by the metabolic activity according to the reduction of XTT to formazan. XTT solution, $0.1 \mathrm{~mL}$ at $0.5 \mathrm{mg} / \mathrm{mL}$ plus menadione $0.1 \mathrm{mM}$ (SigmaAldrich $^{\circledR}$ Inc.), were added to each well and the plates were covered with aluminum foil and incubated at $37^{\circ} \mathrm{C}$ for $3 \mathrm{~h}$. Then, $200 \mu \mathrm{l}$ were plated in triplicate in a 96-well plate and analyzed by absorbance at $550 \mathrm{~nm}$ using a chemiluminescence microreader (ELx 800; BioTek Instruments Inc., Winooski, VE, United States).

\section{Microglial Cell Culture and NO Quantification}

The BV-2 cell line (BCRJ code 0356) was used to evaluate nitric oxide (NO) induction by Candida spp. in vitro. C. albicans 
(SC5314) and the three non-albicans Candida species were grown in YEPD broth (Difco) during $24 \mathrm{~h}$. BV-2 cells were plated on glass slides into 24 -well plates at $5 \times 10^{5}$ cells/well in DMEM High Glucose medium supplemented with $10 \%$ heat-inactivated fetal calf serum (Gibco BRL) and $1 \%$ of sodium pyruvate (SigmaAldrich). After $2.5 \mathrm{~h}$, Candida spp. were added in the same proportion, $5 \times 10^{5}$ yeast/well, and the plate was incubated in $5 \% \mathrm{CO}_{2}$ in a humidified incubator. After incubation time intervals of 6,18 or $24 \mathrm{~h}$, the supernatants were collected and NO levels were determined according to the method described by Green et al. (1981) (41) and cells adhered in the glass slides were stained with panoptic (Laborclin, Pinhais, PR, Brazil). Nitrite accumulation was then quantified using a chemiluminescence microreader (ELx 800; BioTek Instruments Inc., Winooski, VE, United States). The concentration of nitrite was determined using sodium nitrite (Sigma-Aldrich) diluted in distilled water as a standard.

\section{Phylogenetic Analysis}

Sequences deposited at the Protein Database of the NCBI (National Center for Biotechnology and Information) were obtained for analyzed species by blasting at the BLAST tool ${ }^{1}$ of the same institution by using the protein sequence of SSA1 protein of Saccharomyces cerevisiae S288C (accession number NP009396.2). The sequences were aligned with a PAM matrix and the phylogenetic construction was made by using the Maximum Likelihood method based on the Le and Gascuel model (Le and Gascuel, 2008) applying a bootstrap of 1000 replicates (Felsenstein, 1985). Candida albicans 12C (Accession number KGT72617.1) was used as outgroup. The accession number of each sequence is included within parenthesis in Figure 1D. The analysis was made by using the software MEGA v7.0 (Kumar et al., 2016).

${ }^{1}$ https://blast.ncbi.nlm.nih.gov/Blast.cgi

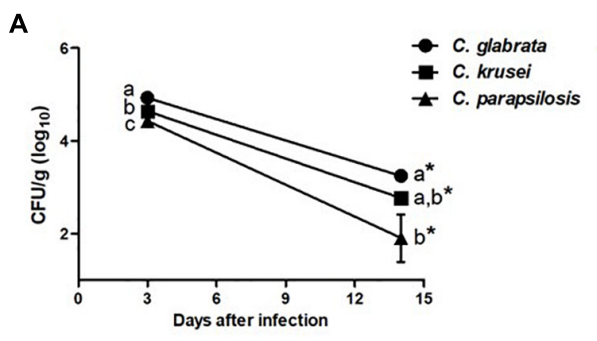

\section{D}

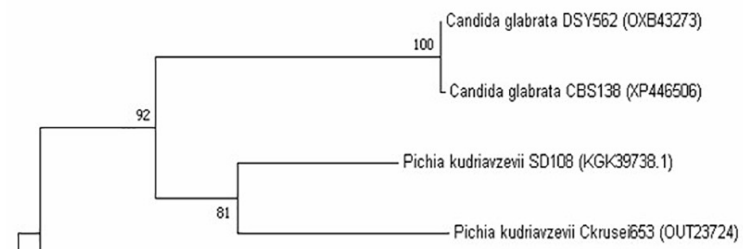

B
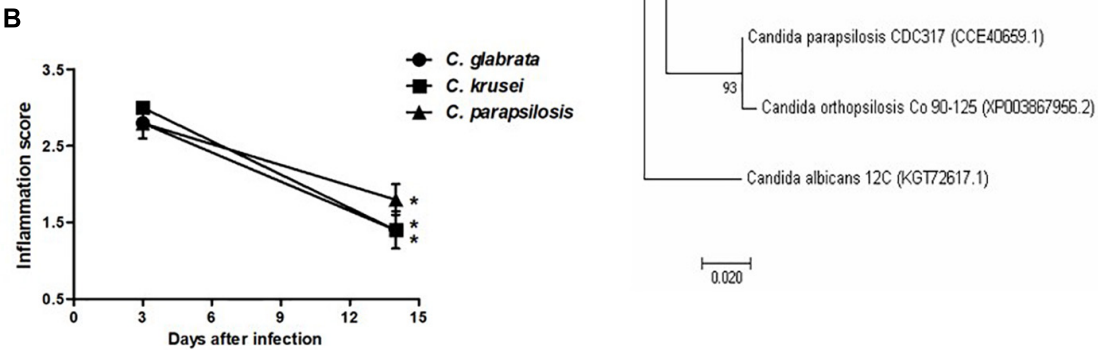

C

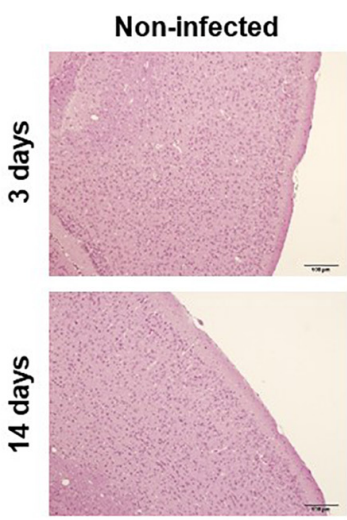

c. glabrata

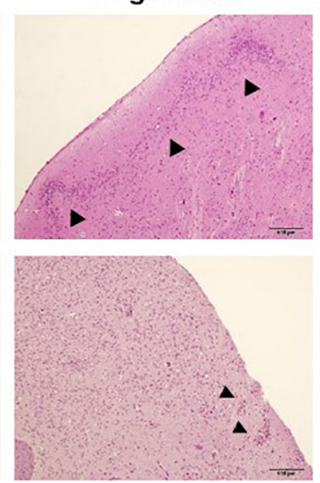

C. krusei

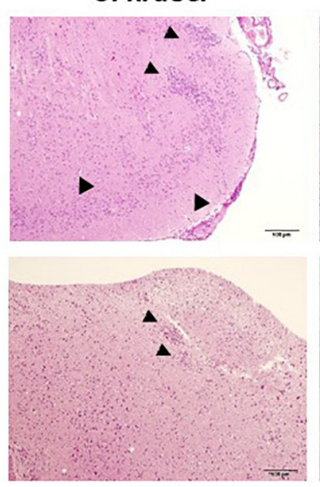

C. parapsilosis

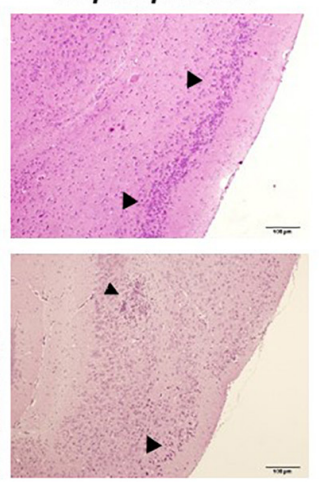

FIGURE 1 | Non-albicans Candida dissemination to the brain in immunocompetent mice. Brain fungal load (A), inflammation score (B), and inflammatory infiltration (C) of Candida glabrata, Candida krusei, and Candida parapsilosis in brain samples were evaluated at 3 and 14 days after infection. The results are expressed as mean \pm SEM; * indicate statistical difference between 3 and 14 days analyzed by unpaired $t$-test; different letters indicate statistical difference among groups analyzed by One-way ANOVA with post hoc Tukey test; $p<0.05 ; n=5 /$ group. Arrowheads indicate diffuse inflammatory infiltration and focus of inflammatory infiltration. Phylogenetic construction of SSA1 protein (D) for C. glabrata, C. krusei (Pichia kudriavzevii) and C. parapsilosis. The percentage of trees in which the associated taxa clustered together is shown next to the branches. 


\section{Statistical Analysis}

The results were initially analyzed by Shapiro-Wilk's test, to test for the normality of data. Comparisons between two samples were made by $t$-test and three or more samples were made by One Way ANOVA followed by Tukey's test. Data were analyzed using SigmaPlot statistical package for Windows version 12.0 (Jandel Corporation, CA, United States) and values of $p<0.05$ were considered statistically significant. Graphs and figures were made in GraphPad Prism 7 (GraphPad Software Inc., San Diego, California, United States). Results were expressed as mean \pm standard error of mean (SEM).
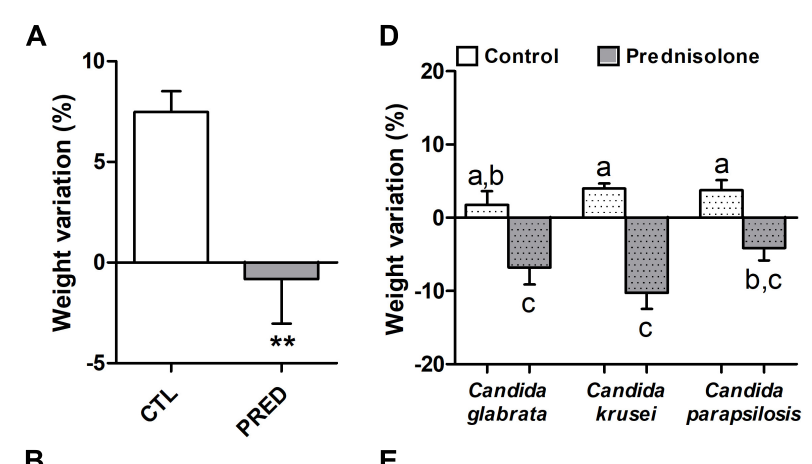

B

E
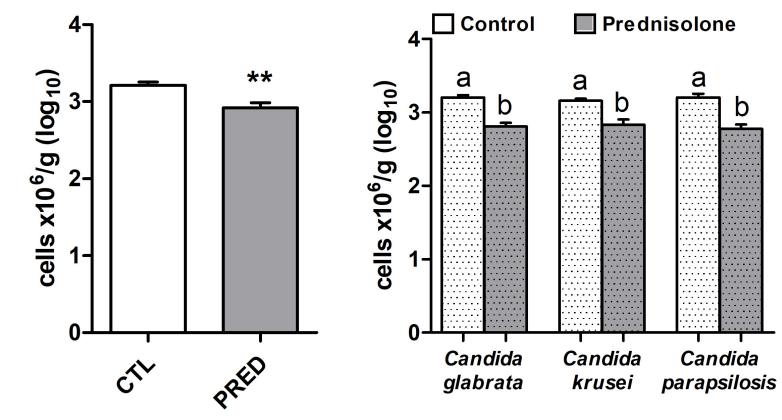

C

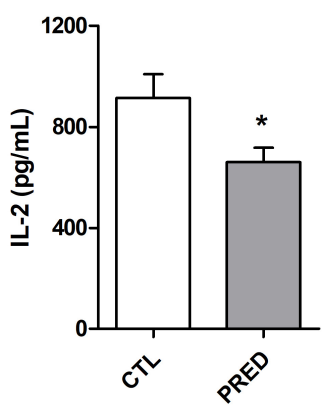

$\mathbf{F}$

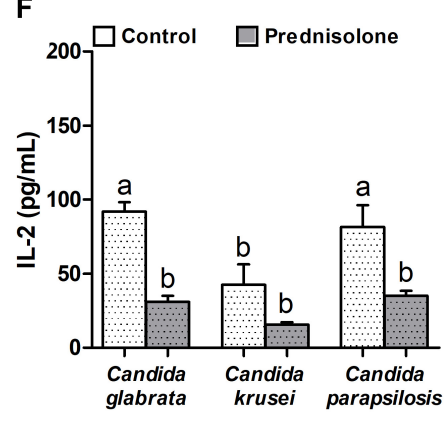

\section{RESULTS}

\section{Non-albicans Candida Disseminate to the Brain of Immunocompetent Mice}

Mice were infected with C. glabrata, C. krusei or C. parapsilosis and evaluated 3 and 14 days after infection. All three Candida spp. were able to spread to the brain and to trigger a local inflammatory process at the third day. As shown in Figure 1A, the three species presented a significantly decreased fungal load on day 14. C. glabrata fungal load was the highest, C. parapsilosis was the lowest and C. krusei presented an intermediate burden in both analyzed periods. Histopathologic scoring revealed that inflammation, similarly to fungal load, was also decreased 14 days after infection (Figure 1B). As illustrated at Figure 1C, all three Candida spp. induced inflammation at the brain meninges and parenchyma (gray matter and white matter). As SSA1 is a fungal invasin that allows $C$. albicans trafficking to the brain, we used a bioinformatics approach to investigate the presence of this protein in the three non-albicans Candida species. The phylogenetic construction performed considering the SSA1 protein revealed that $C$. parapsilosis is phylogenetically more distant comparing to the other two species (C. glabrata and C. krusei) that clustered together within the same clade (Figure 1D).

\section{Prednisolone Affects Body Weight, Leukocyte Number and IL-2 Production}

Prednisolone treatment was associated with significant body weight loss in normal (non-infected) and also in mice infected with any of the three Candida species, as shown in Figures $\mathbf{2 A}$ and $\mathbf{D}$, respectively. Efficacy of corticotherapy was supported by reduction in both, splenic leukocyte number and IL-2 production. Lower cell numbers are illustrated at Figures $\mathbf{2 B}$ and $\mathbf{E}$ for normal and infected mice, respectively. Decreased IL-2 production is displayed in Figures 2C and F for normal and infected mice, respectively.

\section{Non-albicans Candida Species: Biofilm Formation and Prednisolone Effect on Fungal Load and Cytokine Production in Spleen}

Concerning biofilm formation, C. albicans was introduced in this experiment as a positive control. The biofilm formation was checked at different time points. As expected, C. albicans was already able to form biofilm after $6 \mathrm{~h}$ when biofilm was not detected in non-albicans Candida species. After $24 \mathrm{~h}$ incubation, a very clear difference was observed and indicated that, similarly to $C$. albicans, C. glabrata was also able to trigger biofilm formation (Figure 3A). Distinctly from these species, C. krusei and C. parapsilosis had a poor biofilm forming ability (Figure 3A). This elevated ability to trigger a biofilm coincided with the highest splenic fungal load determined by C. glabrata (Figure 3B). Differently from 
C. glabrata and C. parapsilosis whose splenic fungal burdens were not affected by the corticoid treatment, C. krusei fungal load was significantly higher in prednisolone-treated mice (Figure 3B). From the six tested cytokines, four of them, TNF- $\alpha$, IL-6, IL-5 and IL-10, were significantly higher in prednisolone-treated mice (Figures 3C,D,G,H); with exception of IL-5 in C. glabrata infected mice. Differently from other cytokines, IFN- $\gamma$ and IL-17 production was not affected by corticotherapy (Figures 3E,F). However, IFN- $\gamma$ and IL-17 levels were clearly different in C. krusei infection; these cytokines were significantly lower in C. krusei in both, normal and immunosuppressed mice, in comparison to C. glabrata and C. parapsilosis.

\section{Prednisolone Therapy Enhances Fungal Load and Inflammation at the CNS}

Mice infected with C. glabrata, C. krusei or C. parapsilosis were treated with prednisolone and evaluated 14 days after the infection. Prednisolone treatment usually increased fungal load at both, the brain (Figure 4A) and the spinal cord (Figure 4B). The only exception was the amount of fungi recovered from the spinal cord of C. glabrata-infected mice that was similar in immunocompetent and immunosuppressed mice (Figure 4B). Treatment with prednisolone significantly increased brain inflammation only in C. krusei infected mice (Figure 4C). Presence of inflammatory infiltrates in the brain of immunocompetent and immunosuppressed mice is represented in Figure 4D. Spinal cord from infected mice presented no visible inflammation when analyzed in HE stained sections.

\section{C. krusei Infection Triggers Th1 Neuroinflammation in Immunosuppressed Mice}

Quantification of mRNA transcription factors indicated that Gata3 (Th2 signature) was downmodulated by prednisolone in C. krusei-infected mice (Figure 5A). Rorc (Th17 signature) and Foxp3 (Treg signature) were similarly expressed in the brain of prednisolone treated and non-treated infected mice (Figures 5B,C). In addition, no differences were observed concerning the three Candida spp. However, clear differences were detected when the Th1 subset was evaluated. C. krusei immunosuppressed mice showed a higher mRNA expression of Tbx21, IFN- $\gamma$ and TNF- $\alpha$ compared to C. krusei immunocompetent mice (Figures 5D-F). Additionally, this group showed a higher mRNA expression of Dectin-1 and TLR-2 compared to C. krusei immunocompetent mice (Figures 5G,H), but no difference was observed in TLR-4 mRNA expression (Figure 5I).

\section{C. krusei Induces Higher NO Production and Yeast-to-Hyphae Transition in Microglia}

A microglial cell lineage (BV-2) was infected with the different Candida species, including C. albicans, to test and compare their ability to produce nitric oxide (NO) and also their potential to go through yeast-to-hypha transition. C. krusei was clearly the most potent NO inducer; its levels were clearly different from the other species being significantly elevated after 6,18 , and $24 \mathrm{~h}$ after infection (Figure 6A). C. albicans was used as a control and, as expected, hypha formation was already occurring after $6 \mathrm{~h}$ of

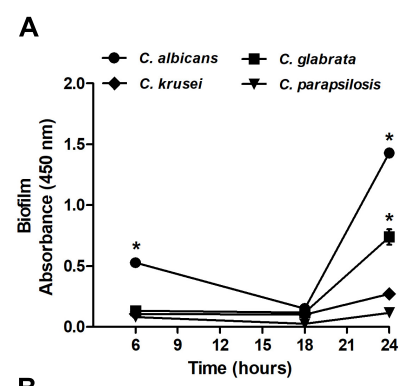

B

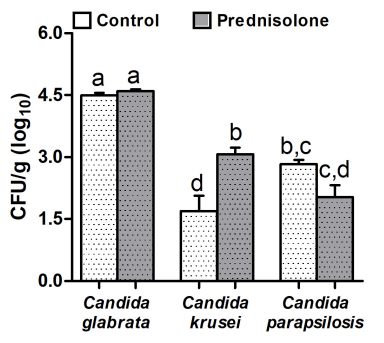

C
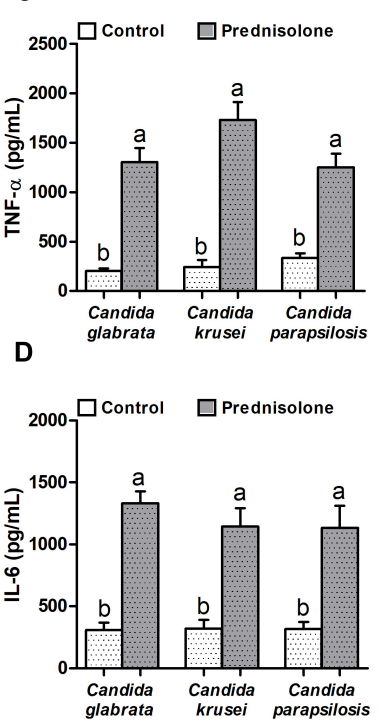

E
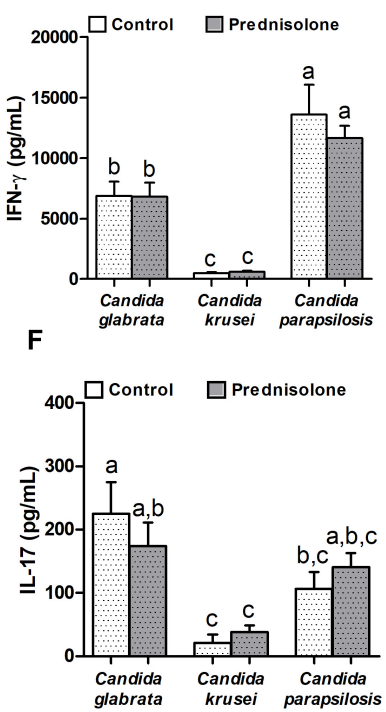

G
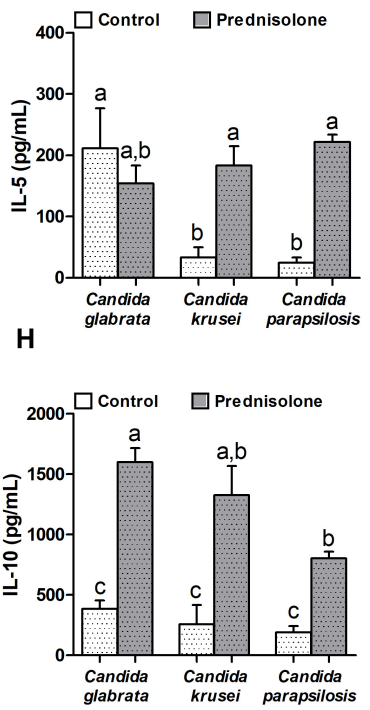

FIGURE 3 | Non-albicans Candida species: biofilm formation and effect of prednisolone on fungal load and cytokine production in spleen. Absorbance of in vitro biofilm assay (A), spleen fungal load (B), and production of TNF- $\alpha$ (C), IL-6 (D), IFN- $\gamma$ (E), IL-17 (F), IL-5 (G) and IL-10 (H) by spleen cell cultures of immunocompetent (Control) and immunosuppressed (Prednisolone) infected-mice. The results are expressed as mean \pm SEM; * and different letters indicate statistical difference among groups analyzed by One-way ANOVA with post hoc Tukey test; $p<0.05 ; n=8$ /group or $n=3 /$ group in biofilm assay. 


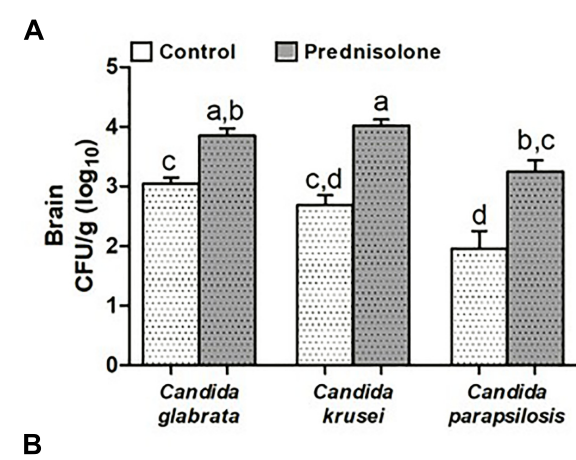

D

B

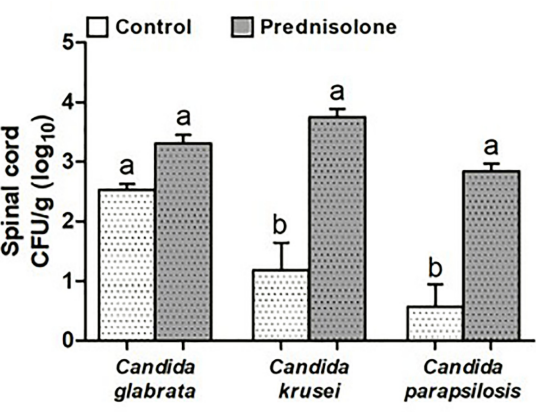

C
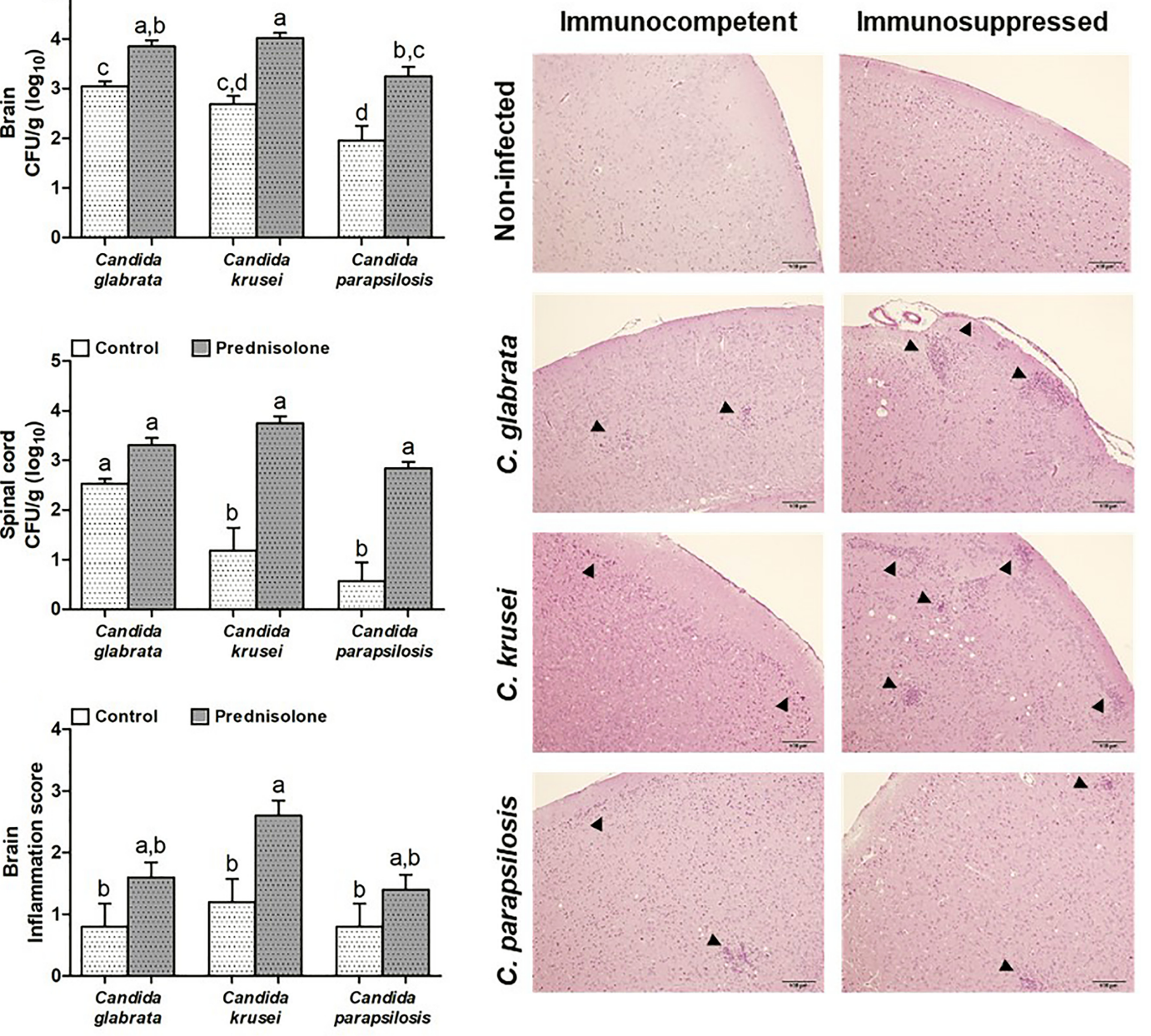

FIGURE 4 | Effect of prednisolone on fungal load and inflammation at the CNS. Fungal load of C. glabrata, C. krusei and C. parapsilosis in brain (A) and spinal cord (B) samples and inflammation score (C) in brain (D) of immunocompetent and immunosuppressed infected mice. The results are expressed as mean \pm SEM (different letters indicate statistical difference among groups analyzed by One-way ANOVA with post hoc Tukey test; $p<0.05 ; n=8$ for CFU and $n=5$ for inflammation score). Arrowheads indicate diffuse inflammatory infiltration and focus of inflammatory infiltration.

incubation. At this time-point, a transition from yeast-to-hypha was already beginning at C. krusei infected cells. As indicated by micrographs, pseudohypha of C. krusei are already coming out of the BV-2 cells after 18 and $24 \mathrm{~h}$. The yeast-to-hypha transition was not detected in C. glabrata and C. parapsilosis infected cells in any tested time-points. These results are illustrated at Figure 6B.

\section{DISCUSSION}

The prevalence of fungal infections is increasing during the past few years. Even though some fungi can trigger pathologies in health subjects, most of these agents provoke illness in previously immunocompromised hosts (Góralska et al., 2018). High risk groups include HIV-infected persons and aids patients, transplant receivers and patients under immunosuppression therapy (Lionakis and Kontoyiannis, 2003; Chastain et al., 2017;
Nel et al., 2018). The involvement of the CNS during fungal infections is primarily found in immunocompromised hosts being Cryptococcus, Aspergillus, and Candida more frequently identified (Henao and Vagner, 2011; Gavito-Higuera et al., 2016).

In a previous report we demonstrated that a systemic infection by Candida albicans disseminates to the CNS and significantly increases the severity of experimental autoimmune encephalomyelitis that is a mouse model for MS (FragaSilva et al., 2015). As the potential of non-albicans Candida species to reach the CNS is not being properly investigated, we used experimental murine infection to compare the ability of C. glabrata, C. krusei and C. parapsilosis to reach the CNS and to cause a local inflammation. To mimic the more frequent situation in which installation at the CNS is more prevalent in immunosuppressed subjects, mice were also acutely immunosuppressed by prednisolone therapy just before experimental infection. 
A

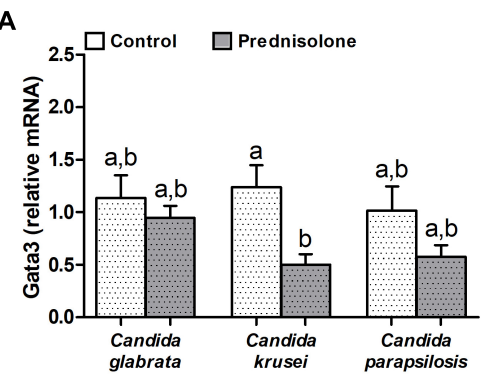

B

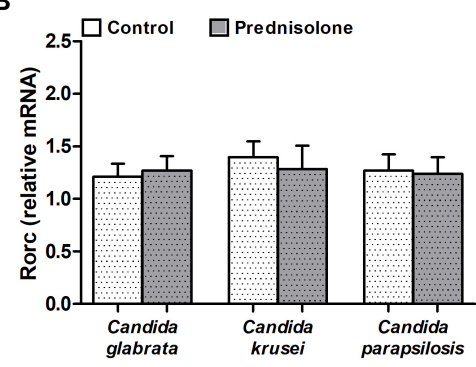

C

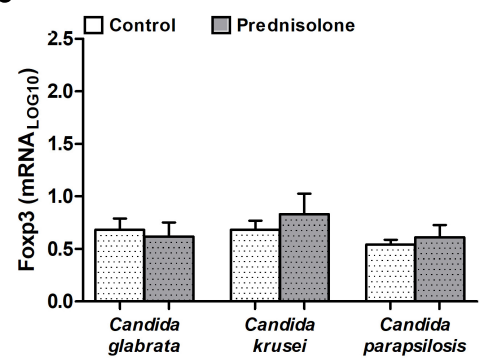

D

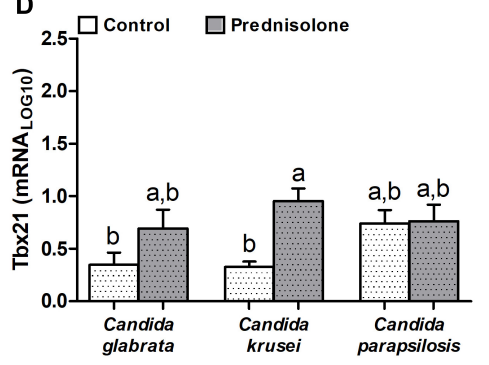

E

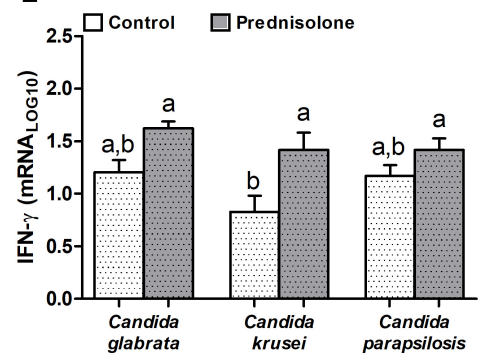

$\mathbf{F}$

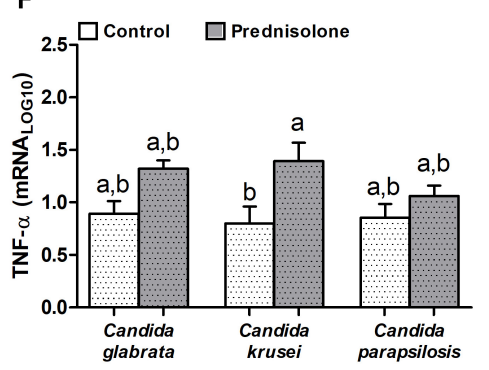

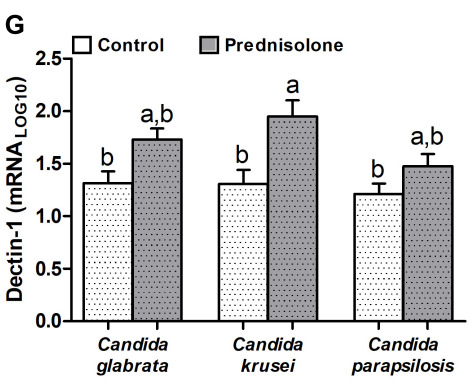

H

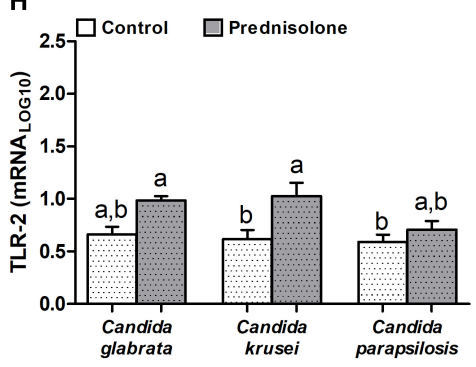

I

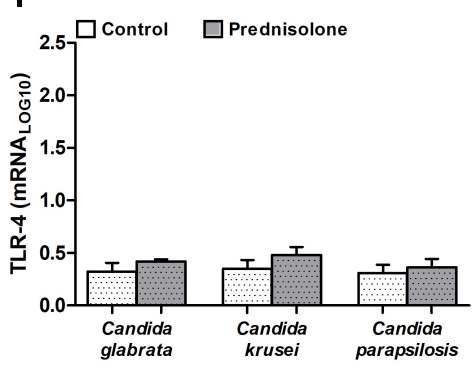

FIGURE 5 | Increased mRNA expression for pro-inflammatory markers in the brain of immunosuppressed $C$. krusei infected mice. Relative mRNA expression of GATA3 (A), RORc (B), Foxp3 (C), Tbx21 (D), IFN- $\gamma$ (E), TNF- $\alpha$ (F), Dectin-1 (G), TLR-2 (H), and TLR-4 (I) in brain samples of immunocompetent (Control) and immunosuppressed (Prednisolone) infected mice. The results are expressed as mean \pm SEM (different letters indicate statistical difference among groups analyzed by One-way ANOVA with post hoc Tukey test; $p<0.05 ; n=6)$.

All three non-albicans Candida species were able to reach the brain in immunocompetent mice and to cause local inflammation. However, both fungal and inflammation clearly subsided 2 weeks after infection. As C. glabrata was present in the brain in higher amount than the two other species, their ability to form a biofilm was compared in vitro. The biofilm forming ability of C. glabrata was elevated being similar to the one formed by C. albicans, which was used as a positive control, and could, at least partially, explain its higher fungal load at both brain and spleen. This finding is important because after C. albicans, C. glabrata is considered one of the most prevalent pathogenic fungi in the human population (Rodrigues et al., 2017). In addition, its strong capacity to form biofilm is described as one of its most consistent virulence factors (Fonseca et al., 2014). The SSA1 protein, an invasin-like molecule, plays a central role in the virulence of Candida. This protein is important for brain invasion since it also induces endocytosis by HBEMCs (Liu et al., 2011). A bioinformatics approach allowed us to identify this protein in the three non-albicans Candida species and also to build a phylogenetic tree. This construction revealed that C. parapsilosis is phylogenetically more distantly related to the other two species (C. glabrata and C. krusei) that clustered together within the same clade. These results are in agreement with the fungal loads in the brain since the three species were able to reach the CNS but the fungal burdens differed among them.

To investigate the effect of an acute state of immunosuppression on peripheral fungal load and immune response, we employed the prednisolone treatment protocol described by Takakura et al. (2003). This procedure significantly reduced body weight in both, normal and infected mice with any of the three Candida species. This finding indicated that corticotherapy was efficient since it is well documented that this drug triggers catabolic effects on skeletal muscles (Sali et al., 2012). A reduced splenic cell number in both, infected and non-infected mice, additionally supported the effectiveness of corticotherapy. Even though the total number of $\mathrm{T}$ cells in the spleen was not determined, the reduced spleen cell number was possibly due to $\mathrm{T}$ cell apoptosis that has been consistently associated with corticosteroid effects (Herold et al., 2006). This possibility was reinforced by the decreased production of IL-2, 
A

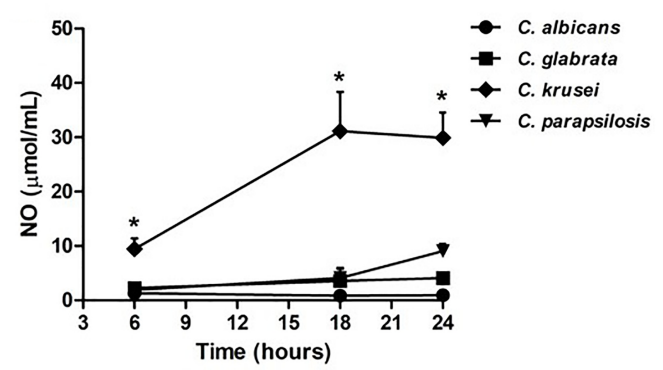

B

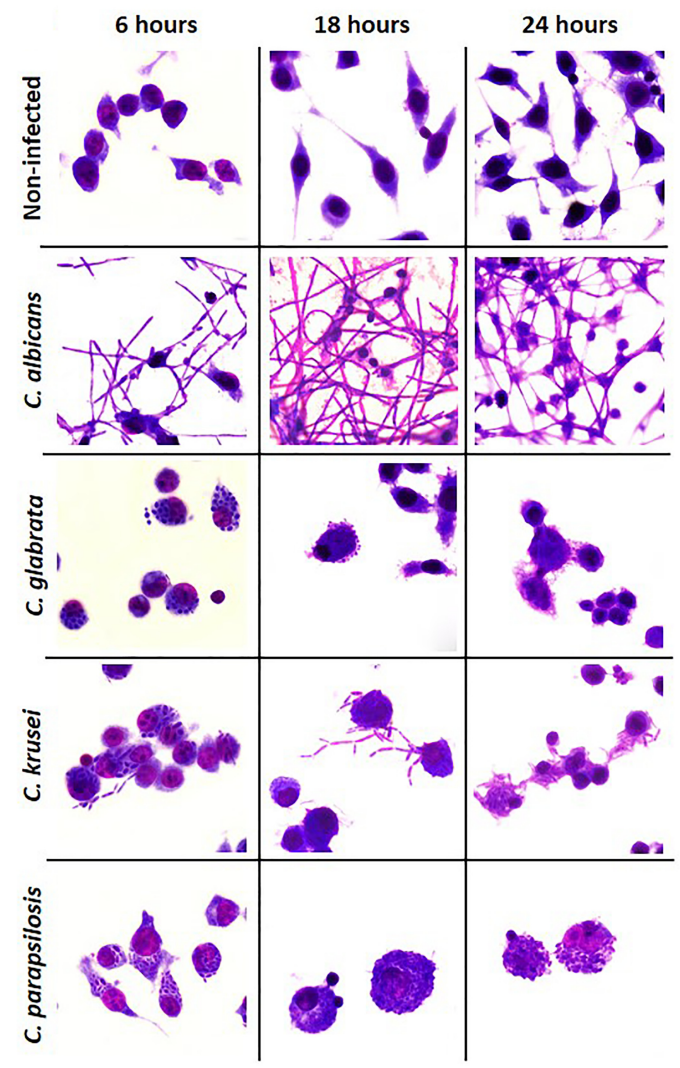

FIGURE 6 | Candida krusei triggers higher NO production and yeast-to-hyphae transition in microglia. Nitric oxide (NO) levels (A) were measured in the supernatant of microglial cell $\left(5 \times 10^{5} /\right.$ well) co-cultured with C. albicans, C. glabrata, C. krusei and C. parapsilosis ( $5 \times 10^{5}$ yeasts/well) at 6,18 , and $24 \mathrm{~h}$ after incubation $\mathbf{( B )}$. The results are expressed as mean \pm SEM $(*$ indicate statistical difference among groups analyzed by One-way ANOVA with post hoc Tukey test; $p<0.05 ; n=3$ /group).

that is the main $\mathrm{T}$ cell growth factor and that is also produced by these cells. Inhibition of cytokine production, including IL-2 production, is broadly accepted as a very relevant mechanism involved in corticoid immunosuppressive effect (Riccardi et al., 2002).

The analysis of peripheral cytokine production together with the splenic fungal load suggested that these three nonalbicans Candida species interact distinctly with the host. Considering IFN- $\gamma$ production, for example, that is required for optimal phagocyte activation and favors the induction of Th1 protective response in C. albicans infections (Gozalbo et al., 2014), the results indicated that C. glabrata and C. parapsilosis induce significant levels of this cytokine. Interestingly, C. parapsilosis induces more IFN- $\gamma$ and controls better the infection. Contrasting with the two other tested species, C. krusei induced very low levels of IFN- $\gamma$ and IL-17 that are signature cytokines denoting Th1 and Th17 presence, respectively (Raphael et al., 2015), suggesting that, at least at the periphery, this infection is not controlled by the classical Th1 and Th17 subsets.

Unexpectedly, an elevated production of some cytokines was observed precisely at the groups that were treated with prednisolone. This was the case of TNF- $\alpha$, IL- 6 and IL-10 in immunosuppressed mice infected with the three species and of IL-5 in immunosuppressed mice infected with C. krusei and C. parapsilosis. A possible differential effect of prednisolone in innate and adaptive immunity could explain this finding. We therefore suggest that the very well described and established downmodulatory effect of corticosteroids on adaptive immunity (Coutinho and Chapman, 2011; Olnes et al., 2016) is associated with a concomitant enhancement of, at least, some aspects of innate immunity. High doses of glucocorticoids induced apoptosis of T cells and other immune cells such as thymocytes, $\mathrm{B}$ cells, macrophages, mature dendritic cells, eosinophils, and natural killer cells (Gruver-Yates and Cidlowski, 2013), but did not affect monocytes and neutrophils (Serra-Bonett et al., 2009). Even though the literature concerning this subject is very scarce and also indirect, this possibility is supported by some findings as the presence of neutrophilic leukocytosis in children with nephrotic syndrome being treated with systemic corticosteroids (Bariş et al., 2016) and enhanced survival and function of neutrophils and alveolar macrophages by inhaled glucocorticoids (Schleimer, 2004). Interestingly, during systemic candidiasis there is an accumulation of neutrophils in all organs, except the brain (Lionakis et al., 2011) and these cells are able to produce a plethora of cytokines including, for example, TNF- $\alpha$, IL-6, IL-10 and IL-5 (Tecchio et al., 2014; Xu et al., 2017) that were found elevated in spleen cell cultures from prednisolone treated mice, as described above.

Contrasting with the effect of corticotherapy on spleen fungal recovery that increased only the amount of C. krusei, the prednisolone treatment determined a significant increase in the CNS fungal load of the three Candida species. This findings seems very relevant because it strongly supports that corticotherapy, and possible other immunosuppressive drugs, are able to facilitate fungal dissemination to the CNS as has already being evidenced (Sharma, 2010). CNS invasion by these non-albicans Candida species deserves attention and investigations concerning not only their contribution as causes of meningitis, cerebritis and abscess formation (Gavito-Higuera et al., 2016) but also as possible triggers or aggravators of neurodegenerative pathologies as Alzheimer (Fulop et al., 2018) and MS (Benito-León and Laurence, 2017).

In spite of this similar and significant dissemination of these Candida species to the CNS in immunosuppressed mice, a very distinct local inflammatory scenario was observed in the 
brain. C. glabrata and C. parapsilosis behaved similarly, that is, they triggered a slightly increased inflammation in previously suppressed mice. However, the brain of mice treated with prednisolone before C. krusei infection displayed a significantly enhanced inflammatory infiltrate. The local analysis of mRNA expression revealed that $C$. krusei infected mice presented an elevated expression of many pro-inflammatory markers, including some as Tbx21, IFN- $\gamma$ and TNF- $\alpha$ that highly suggested a local Th1 polarization. Additionally, mRNA of pattern recognition receptors (PRRs) as dectin-1 and toll-like receptor (TLR)-2, present in innate immune cells, was increased in immunosuppressed mice, and especially in mice infected with C. krusei. Dectin-1 is a PRR that binds $\beta$-glucans and collaborates with TLR-2 receptor for inflammatory activation of phagocytes against Candida spp., including macrophages (Gantner et al., 2005; Xu et al., 2015), that are predominantly activated by Th1 subset.

To further understand the host-parasite interaction in CNS, we tested NO production and yeast-to-hypha or pseudohypha transition in microglial cells lineage infected with Candida species. Microglia is the resident phagocyte of the CNS and this cell type was chosen because it is the main cell involved in the control of fungal colonization in the CNS (Koutsouras et al., 2017). The results indicated that C. krusei was very distinct from the two other non-albicans Candida species; it induced much higher NO levels and was the only one able to switch from yeast-to-pseudohypha.

Innate immune cells as macrophages and microglia produce reactive oxygen and nitrogen (ROS and RNS) species, including high levels of NO, against pathogens. However, pathogens have evolved many strategies to escape from NO effects. A wide variety of microbes including bacteria and fungi, especially C. albicans, can detoxify NO using flavohemoglobins detoxification enzymes, that confer resistance to NO microbicidal effect (Hromatka et al., 2005). In our study, while very low NO levels were found in C. albicans infected microglia cells, C. krusei infection triggered a significantly higher NO production. This is interesting because $\mathrm{NO}$ is a key regulator of T-bet expression and was directly associated to Th1 subset expansion and Th2 subset suppression (Pahan and Mondal, 2012). In addition, C. krusei and C. parapsilosis are being consistently the most sensitive species to NO (McElhaney-Feser et al., 1998).

Our findings reveal that C. krusei uses different strategies to try to escape from the immune response. This species is able, for example, to switch from yeast-to-pseudohypha inside microglial cells while C. glabrata and C. parapsilosis remain in the yeast form inside these cells. Moreover, it is already described that C. krusei induces vomocytosis to avoid destruction by macrophages (García-Rodas et al., 2011). This process consists of fungal expulsion from the macrophage without lysing the host cells (Gilbert et al.,

\section{REFERENCES}

Andersson, A. K., Chaduvula, M., Atkinson, S. E., Khanolkar-Young, S., Jain, S., Suneetha, L., et al. (2005). Effects of prednisolone treatment on cytokine expression in patients with leprosy type 1 reactions.
2015). A similar process was reported in C. albicans (Bain et al., 2012) and corroborates our in vitro data. In summary, we hypothesize that C. krusei early induction of NO could contribute to Th1 differentiation. However, this species would be able to escape from macrophage's microbicidal activity by vomocytocis.

Altogether these results indicate that C. glabrata, C. krusei and C. parapsilosis, similarly to C. albicans, are also able to disseminate to the CNS and promote local inflammation. In addition, the findings clearly show that corticotherapy increases their respective fungal loads at both, the brain and the spinal cord, being C. krusei the species that triggers the highest local accumulation of Th1 cells. It is possible that the neuroinflammation triggered by this type of Th1-inducing Candida is even more deleterious to CNS pathologies originally associated to Th1 immunopathogenesis. Considering also that CNS samples are difficult to obtain from patients, we believe that experimental models can be widely explored to investigate the effect of these fungi infections in many CNS disorders such as multiple sclerosis, Parkinson's and Alzheimer's diseases.

\section{ETHICS STATEMENT}

The animals were manipulated in accordance with the Brazilian legislation that is regulated by the National Council for the Control of Animal Experimentation (CONCEA) and by the Ethical Principles in Animal Research formulated by the Brazilian Society of Science in Laboratory Animals. The whole experimental protocol was also approved by the Medical School Ethics Committee on Use of Animals (CEUA - protocol number 1206/2017), UNESP, Botucatu, SP, Brazil.

\section{AUTHOR CONTRIBUTIONS}

MS, AS, CK, and TF-S conceived and designed the experiments. MS, LM, LO, LI, and TF-S performed the experiments and contributed to immunological and histopathological analysis tools. HG, EB, and TF-S contributed to biofilm and bioinformatics analysis tools. MS, AS, and TF-S analyzed the data and wrote the manuscript. All authors approved the final version to be published.

\section{FUNDING}

This research was supported by National Council for Scientific and Technological Development (CNPq - grant 307269/2017-5), Brazil. Additionally, TF-S was supported by a postdoctoral fellowship from the CNPq (grant 152790/2016-0).

Infect. Immun. $\quad 73, \quad 3725-3733$. doi: 10.1128/IAI.73.6.3725-37 33.2005

Bain, J. M., Lewis, L. E., Okai, B., Quinn, J., Gow, N. A., and Erwig, L. P. (2012). Non-lytic expulsion/exocytosis of Candida albicans from macrophages. Fungal Genet. Biol. 49, 677-678. doi: 10.1016/j.fgb.2012.01.008 
Bariş, H. E., Kiykim, A., Nain, E., Özen, A. O., Karakoç-Aydiner, E., and Bariş, S. (2016). The plethora, clinical manifestations and treatment options of autoimmunity in patients with primary immunodeficiency. Turk Pediatri Ars. 51, 186-192. doi: 10.5152/TurkPediatriArs.2016.3928

Benito-León, J., and Laurence, M. (2017). The role of fungi in the etiology of multiple sclerosis. Front. Neurol. 16:535. doi: 10.3389/fneur.2017. 00535

Benito-León, J., Pisa, D., Alonso, R., Calleja, P., Díaz-Sánchez, M., and Carrasco, L. (2010). Association between multiple sclerosis and Candida species: evidence from a case-control study. Eur. J. Clin. Microbiol. Infect. Dis. 29, 1139-1145. doi: 10.1007/s10096-010-0979-y

Bertini, A., Zoppo, M., Lombardi, L., Rizzato, C., De Carolis, E., Vella, A., et al. (2016). Targeted gene disruption in Candida parapsilosis demonstrates a role for CPAR2_404800 in adhesion to a biotic surface and in a murine model of ascending urinary tract infection. Virulence 7, 85-97. doi: 10.1080/21505594. 2015.1112491

Chastain, D. B., Stover, K. R., and Riche, D. M. (2017). Evidence-based review of statin use in patients with HIV on antiretroviral therapy. J. Clin. Transl. Endocrinol. 22, 6-14. doi: 10.1016/j.jcte.2017.01.004

Coutinho, A. E., and Chapman, K. E. (2011). The anti-inflammatory and immunosuppressive effects of glucocorticoids, recent developments and mechanistic insights. Mol. Cell Endocrinol. 15, 2-13. doi: 10.1016/j.mce.2010. 04.005

De Kruif, M. D., Lemaire, L. C., Giebelen, A. I., Van Zoelen, M. A., Pater, J. M., Van Den Pangaart, P. S., et al. (2007). Prednisolone dose-dependently influences inflammation and coagulation during human endotoxemia. J. Immunol. 178, 1845-1851. doi: 10.4049/jimmunol.178.3.1845

Eggimann, P., Garbino, J., and Pittet, D. (2003). Epidemiology of Candida species infections in critically ill non-immunosuppressed patients. Lancet Infect. Dis. 3, 685-702. doi: 10.1016/S1473-3099(03)00801-6

Faix, R. G., and Chapman, R. L. (2003). Central nervous system candidiasis in the high-risk neonate. Semin. Perinatol. 27, 384-392. doi: 10.1016/S0146-0005(03) 00065-X

Felsenstein, J. (1985). Confidence limits on phylogenies: an approach using the bootstrap. Evolution 39, 783-791. doi: 10.1111/j.1558-5646.1985. tb00420.x

Fonseca, E., Silva, S., Rodrigues, C. F., Alves, C. T., Azeredo, J., and Henriques, M. (2014). Effects of fluconazole on Candida glabrata biofilms and its relationship with $\mathrm{ABC}$ transporter gene expression. Biofouling 30, 447-457. doi: 10.1080/ 08927014.2014 .886108

Fraga-Silva, T. F., Mimura, L. A., Marchetti, C. M., Chiuso-Minicucci, F., França, T. G., Zorzella-Pezavento, S. F., et al. (2015). Experimental autoimmune encephalomyelitis development is aggravated by candida albicans infection. J. Immunol. Res. 2015, 1-11. doi: 10.1155/2015/635052

Fulop, T., Witkowski, J. M., Bourgade, K., Khalil, A., Zerif, E., Larbi, A., et al. (2018). Can an infection hypothesis explain the beta amyloid hypothesis of Alzheimer's Disease? Front. Aging Neurosci. 10:224. doi: 10.3389/fnagi.2018. 00224

Gantner, B. N., Simmons, R. M., and Underhill, D. M. (2005). Dectin-1 mediates macrophage recognition of Candida albicans yeast but not filaments. EMBO J. 24, 1277-1286. doi: 10.1038/sj.emboj.7600594

García-Rodas, R., González-Camacho, F., Rodríguez-Tudela, J. L., CuencaEstrella, M., and Zaragoza, O. (2011). The interaction between Candida krusei and murine macrophages results in multiple outcomes, including intracellular survival and escape from killing. Infect Immun. 79, 2136-2144. doi: 10.1128/ IAI.00044- 11

Gavito-Higuera, J., Mullins, C. B., Ramos-Duran, L., Olivas Chacon, C. I., Hakim, N., and Palacios, E. (2016). Fungal infections of the central nervous system: a pictorial review. J. Clin. Imaging Sci. 6:24. doi: 10.4103/2156-7514. 184244

Gilbert, A. S., Wheeler, R. T., and May, R. C. (2015). Fungal pathogens: survival and replication within macrophages. Cold Spring Harb. Perspect. Med. 5:a019661. doi: $10.1101 /$ cshperspect.a019661

Gold, R., and Wolinsky, J. S. (2010). Pathophysiology of multiple sclerosis and the place of teriflunomide. Acta. Neurol. Scand. 2011, 75-84. doi: 10.1111/j.16000404.2010.01444.x

Góralska, K., Blaszkowska, J., and Dzikowiec, M. (2018). Neuroinfections caused by fungi. Infection 46, 443-459. doi: 10.1007/s15010-018-1152-2
Gozalbo, D., Maneu, V., and Gil, M. L. (2014). Role of IFN-gamma in immune responses to Candida albicans infections. Front. Biosci. 19:1279-1290. doi: 10. $2741 / 4281$

Green, L. C., Tannenbaum, S. R., and Goldman, P. (1981). Nitrate synthesis in the germfree and conventional rat. Science 212, 56-58. doi: 10.1126/science. 6451927

Gruver-Yates, A. L., and Cidlowski, J. A. (2013). Tissue-specific actions of glucocorticoids on apoptosis: a double-edged sword. Cells 2, 202-223. doi: $10.3390 /$ cells 2020202

Henao, N. A., and Vagner, B. (2011). Infections of the central nervous system by Candida. J. Infect. Dis. Immun. 3, 79-84.

Herold, M. J., Mcpherson, K. G., and Reichardt, H. M. (2006). Glucocorticoids in T cell apoptosis and function. Cell. Mol. Life Sci. 63, 60-72. doi: 10.1007/s00018005-5390-y

Hoyer, L. L., Fundyga, R., Hecht, J. E., Kapteyn, J. C., Klis, F. M., and Arnold, J. (2001). Characterization of agglutinin-like sequence genes from non-albicans Candida and phylogenetic analysis of the ALS family. Genetics 157, 1555-1567.

Hromatka, B. S., Noble, S. M., and Johnson, A. D. (2005). Transcriptional response of Candida albicans to nitric oxide and the role of the Yhb1 gene in nitrosative stress and virulence. Mol. Biol. Cell. 16, 4814-4826. doi: 10.1091/mbc.e05-050435

Jong, A. Y., Stins, M. F., Huang, S. H., Chen, S. H., and Kim, K. S. (2001). Traversal of candida albicans across human blood-brain barrier in vitro. Infect. Immun. 69, 4536-4544. july., doi: 10.1128/IAI.69.7.4536-4544.2001

Jordán, I., Hernandez, L., Balaguer, M., López-Castilla, J. D., Casanueva, L., Shuffelman, C., et al. (2014). C. albicans, C. parapsilosis and C. tropicalis invasive infections in the PICU: clinical features, prognosis and mortality. Rev. Esp. Quimioter. 27, 56-62.

Kobayashi-Sakamoto, M., Tamai, R., Isogai, E., and Kiyoura, Y. (2018). Gastrointestinal colonisation and systemic spread of Candida albicans in mice treated with antibiotics and prednisolone. Microb Pathog. 117, 191-199. doi: 10.1016/j.micpath.2018.02.043

Koutsouras, G. W., Ramos, R. L., and Martinez, L. R. (2017). Role of microglia in fungal infections of the central nervous system. Virulence 8, 705-718. doi: 10.1080/21505594.2016.1261789

Kumar, S., Stecher, G., and Tamura, K. (2016). MEGA7: molecular evolutionary genetics analysis version 7.0 for bigger datasets. Mol. Biol. Evol. 33, 1870-1874. doi: $10.1093 / \mathrm{molbev} / \mathrm{msw} 054$

Le, S. Q., and Gascuel, O. (2008). An improved general amino acid replacement matrix. Mol. Biol. Evol. 25, 1307-1320. doi: 10.1093/molbev/msn067

Li, H., Gong, H., Qi, Y., Li, J., Sun, J., Tian, R., et al. (2017). In vitro and in vivo antifungal activities and mechanism of heteropolytungstates against Candida species. Sci. Rep. 7, 1-9. doi: 10.1038/s41598-017-17239-8

Lionakis, M. S., and Kontoyiannis, D. P. (2003). Glucocorticoids and invasive fungal infections. Lancet 362, 1828-1838. doi: 10.1016/S0140-6736(03)14904-5

Lionakis, M. S., Lim, J. K., Lee, C. C., and Murphy, P. M. (2011). Organ-specific innate immune responses in a mouse model of invasive candidiasis. J. Innate Immun. 3, 180-199. doi: 10.1159/000321157

Liu, Y., Mittal, R., Solis, N. V., Prasadarao, N. V., and Filler, S. G. (2011). Mechanisms of Candida albicans trafficking to the brain. PLoS Pathog. 7:e1002305. doi: 10.1371/journal.ppat.1002305

Mattson, M. P. (2012). Energy intake and exercise as determinants of brain health and vulnerability to injury and disease. Cell Metab. 16, 706-722. doi: 10.1016/j. cmet.2012.08.012

McElhaney-Feser, G. E., Raulli, R. E., and Cihlar, R. L. (1998). Synergy of nitric oxide and azoles against candida species in vitro. Antimicrob. Agents Chemother. 42, 2342-2346. doi: 10.1128/AAC.42.9.2342

Murthy, J. M. K., and Sundaram, C. (2014). Fungal infections of the central nervous system. Handb. Clin. Neurol. 121, 1383-1401. doi: 10.1016/B978-0-7020-40887.00095-X

Nel, J. S., Bartelt, L. A., Van Duin, D., and Lachiewicz, A. M. (2018). Endemic mycoses in solid organ transplant recipients. Infect. Dis. Clin. North Am. 32, 667-685. doi: 10.1016/j.idc.2018.04.007

Olnes, M. J., Kotliarov, Y., Biancotto, A., Cheung, F., Chen, J., Shi, R., et al. (2016). Effects of systemically administered hydrocortisone on the human immunome. Sci. Rep. 6:23002. doi: 10.1038/srep23002

Pahan, K., and Mondal, S. (2012). Crosstalk between nitric oxide and thelper cells. J. Clin. Cell Immunol. 3:e109. doi: 10.4172/2155-9899.1000e109 
Panackal, A. A., and Williamson, P. R. (2015). Fungal infections of the central nervous system. Continuum 21, 1662-1678. doi: 10.1212/CON. 0000000000000241

Pfaller, M. A., Andes, D. R., Diekema, D. J., Horn, D. L., Reboli, A. C., Rotstein, C., et al. (2014). Epidemiology and outcomes of invasive candidiasis due to non-albicans species of candida in 2,496 patients: data from the prospective antifungal therapy (Path) registry 2004-2008. PLoS One 9:e101510. doi: 10. 1371/journal.pone.0101510

Pisa, D., Alonso, R., and Carrasco, L. (2011). Fungal infection in a patient with multiple sclerosis. Eur. J. Clin. Microbiol. Infect. Dis. 30, 1173-1180. doi: 10. 1007/s10096-011-1206-1

Pisa, D., Alonso, R., Jiménez-Jiménez, F. J., and Carrasco, L. (2013). Fungal infection in cerebrospinal fluid from some patients with multiple sclerosis. Eur. J. Clin. Microbiol. Infect. Dis. 32, 795-801. doi: 10.1007/s10096-0121810-8

Pisa, D., Alonso, R., Rábano, A., Rodal, I., and Carrasco, L. (2015). Different brain regions are infected with fungi in alzheimer's disease. Sci. Rep. 5, 1-13. doi: 10.1038/srep15015

Raphael, I., Nalawade, S., Eagar, T. N., and Forsthuber, T. G. (2015). T cell subsets and their signature cytokines in autoimmune and inflammatory diseases. Cytokine 74, 5-17. doi: 10.1016/j.cyto.2014.09.011

Riccardi, C., Bruscoli, S., and Migliorati, G. (2002). Molecular mechanisms of immunomodulatory activity of glucocorticoids. Pharmacol. Res. 45, 361-368. doi: 10.1006/phrs.2002.0969

Rodrigues, C. F., Rodrigues, M. E., Silva, S., and Henriques, M. (2017). Candida glabrata biofilms: how far have we come? J. Fungi 3:11. doi: 10.3390/jof 3010011

Sali, A., Guerron, A. D., Gordish-Dressman, H., Spurney, C. F., Iantorno, M., Hoffman, E. P., et al. (2012). Glucocorticoid-treated mice are an inappropriate positive control for long-term preclinical studies in the $\mathrm{mdx}$ mouse. PLoS One 7:e34204. doi: 10.1371/journal.pone. 0034204

Saroukolaei, S. A., Ghabaee, M., Shokri, H., Badiei, A., and Ghourchian, S. (2016). The role of Candida albicans in the severity of multiple sclerosis. Mycoses 59, 697-704. doi: $10.1111 /$ myc. 12489

Schleimer, R. P. (2004). Glucocorticoids suppress inflammation but spare innate immune responses in airway epithelium. Proc. Am. Thorac. Soc. 1, 222-230. doi: 10.1513/pats.200402-018MS

Serra-Bonett, N., Al Snih, S., and Rodriguez, M. A. (2009). Effect of lowdose prednisone on leukocyte counts and subpopulations in patients with rheumatoid arthritis. J. Clin. Rheumatol. 3, 148-149. doi: 10.1097/RHU. 0b013e3181a3ac2d

Sharma, R. (2010). Fungal infections of the nervous system: current perspective and controversies in management. Int. J. Surg. 8, 591-601. doi: 10.1016/j.ijsu. 2010.07.293

Storti, L. R., Pasquale, G., Scomparim, R., Galastri, A. L., Alterthum, F., Gambale, W., et al. (2012). Candida spp. isolated from inpatients, the environment, and health practitioners in the Pediatric Unit at the Universitary Hospital of the Jundiaí Medical College State of São Paulo Brazil.
Rev. Soc. Bras. Med. Trop. 45, 225-231. doi: 10.1590/S0037-86822012000 200017

Takakura, N., Sato, Y., Ishibashi, H., Oshima, H., Uchida, K., Yamaguchi, H., et al. (2003). A novel murine model of oral candidiasis with local symptoms characteristic of oral thrush. Microbiol. Immunol. 47, 321-326. doi: 10.1111/j. 1348-0421.2003.tb03403.x

Tecchio, C., Micheletti, A., and Cassatella, M. A. (2014). Neutrophil-derived cytokines: facts beyond expression. Front. Immunol. 21:508. doi: 10.3389/ fimmu.2014.00508

Turner, S. A., and Butler, G. (2014). The candida pathogenic species complex. Cold Spring Harb. Perspect. Med. 4, 1-17. doi: 10.1101/cshperspect.a019778

Wu, P. F., Liu, W. L., Hsieh, M. H., Hii, M. I, Lee, Y. L., Lin, Y. T., et al. (2017). Epidemiology and antifungal susceptibility of candidemia isolates of non-albicans Candida species from cancer patients. Emerg. Microbes Infect. 6:e87. doi: 10.1038/emi.2017.74

Xu, J., Guardado, J., Hoffman, R., Xu, H., Namas, R., Vodovotz, Y., et al. (2017). IL33-mediated ILC2 activation and neutrophil IL5 production in the lung response after severe trauma: a reverse translation study from a human cohort to a mouse trauma model. PLoS Med. 14:e1002365. doi: 10.1371/journal.pmed. 1002365

Xu, R., Sun, H. F., Williams, D. W., Jones, A. V., Al-Hussaini, A., Song, B., et al. (2015). IL-34 suppresses candida albicans induced tnf $\alpha$ production in M1 macrophages by downregulating expression of dectin-1 and TLR2. J. Immunol. Res. 2015:328146. doi: 10.1155/2015/328146

Yampolsky, C., Corti, M., and Negroni, R. (2010). Fungal cerebral abscess in a diabetic patient successfully treated with surgery followed by prolonged antifungal therapy. Rev. Iberoam. Micol. 27, 6-9. doi: 10.1016/j.riam.2009.12.001

Yan, S. X., Deng, X. M., Wang, Q. T., Sun, X. J., and Wei, W. (2015). Prednisone treatment inhibits the differentiation of B lymphocytes into plasma cells in Mrl/MpSlac-lpr mice. Acta Pharmacol. Sin. 36, 1367-1376. doi: 10.1038/aps. 2015.76

Yapar, N. (2014). Epidemiology and risk factors for invasive candidiasis. Ther. Clin. Risk Manag. 10, 95-105. doi: 10.2147/TCRM.S40160

Conflict of Interest Statement: The authors declare that the research was conducted in the absence of any commercial or financial relationships that could be construed as a potential conflict of interest.

The reviewer RR declared a shared affiliation, with no collaboration, with the authors HG and EB, to the handling Editor at the time of review.

Copyright (c) 2019 Sanches, Mimura, Oliveira, Ishikawa, Garces, Bagagli, Sartori, Kurokawa and Fraga-Silva. This is an open-access article distributed under the terms of the Creative Commons Attribution License (CC BY). The use, distribution or reproduction in other forums is permitted, provided the original author(s) and the copyright owner(s) are credited and that the original publication in this journal is cited, in accordance with accepted academic practice. No use, distribution or reproduction is permitted which does not comply with these terms. 